\title{
Review
}

\section{Cognitive Interventions in Parkinson's Disease: Where We Want to Go within 20 Years}

\author{
Elke Kalbe $^{\mathrm{a}, *}$, Dag Aarsland ${ }^{\mathrm{b}, \mathrm{c}}$ and Ann-Kristin Folkerts ${ }^{\mathrm{a}}$ \\ ${ }^{a}$ Medical Psychology I Neuropsychology and Gender Studies \& Center for Neuropsychological Diagnostics \\ and Intervention (CeNDI), University Hospital Cologne, Cologne, Germany \\ ${ }^{\mathrm{b}}$ Department of Old Age Psychiatry, Institute of Psychiatry, Psychology and Neuroscience, \\ King's College London, London, United Kingdom \\ ${ }^{\mathrm{c}}$ Centre for Age-Related Medicine, Stavanger University Hospital, Stavanger, Norway
}

Accepted 8 November 2018

\begin{abstract}
Today, meta-analyses demonstrate that cognitive training is safe and effective to enhance vulnerable cognitive functions in patients with Parkinson's disease (PD), so that cognitive interventions can be regarded as a promising approach to treat or even prevent cognitive dysfunction in PD. However, many research gaps exist. Thus, this article aims to identify relevant research topics with regard to cognitive interventions in PD patients for the next 20 years. The most important to do's include the development of (non-digital and digital, maybe also artificial intelligence based) standardized cognitive interventions for PD patients in different cognitive stages and the conduct of large randomized controlled trials (RCTs) in these groups, also considering different patient profiles (e.g., motor subtypes) and the living setting (inpatient versus outpatient). The impact of cognitive and combined interventions in individuals with prodromal PD is of high relevance. Studies should elucidate underlying mechanisms of cognitive and neural plasticity induced by cognitive interventions and propose prediction models on which patients profit from which intervention. Health-economic analyses are also urgently needed. More generally, increasing the awareness of the concept of cognitive reserve and possibilities for the prevention of cognitive dysfunction is an important goal.
\end{abstract}

Keywords: Parkinson's disease, dementia, cognitive dysfunction, cognition, rehabilitation, treatment outcome, clinical trials, medical economics

In 20 years, it is estimated that the prevalence of Parkinson's disease (PD) will be doubled due to changed demographics (cf. increase of 630,000 PD patients in 2010 to 1.24 million people in 2040 in the United States) [1]. A high proportion of these patients will develop cognitive dysfunctions

\footnotetext{
*Correspondence to: Prof. Dr. Elke Kalbe, Medical Psychology |Neuropsychology and Gender Studies \& Center for Neuropsychological Diagnostics and Intervention (CeNDI), University Hospital Cologne, Kerpenerstr. 62, Cologne 50937, Germany. Tel.: +49 221478 96244; Fax: +49 221478 3420; E-mail: elke.kalbe@ukkoeln.de.
}

during the disease (cf. cumulative prevalence of $83 \%$ for Parkinson's disease dementia (PDD) at 20-year follow-up [2, 3]), and it can be assumed that the proportion will even increase longitudinally due to population aging with more older patients.

Today, systematic reviews and meta-analyses demonstrate that cognitive training is safe and effective to enhance cognitive functions with small to large effect sizes depending on the functions trained and assessed [4-7]. For example, two meta-analyses show significant cognitive training effects in executive functions as well as working memory which 
belong to the most vulnerable cognitive functions in PD [5, 6]. Lawrence and colleagues [6] also found a positive impact on memory, while Leung et al. [5] reported further improvements in processing speed. Both studies focused on cognitive training in PD patients without cognitive dysfunctions as well as mild cognitive symptoms. However, only few studies have examined neural correlates of training induced cognitive plasticity [8-10]. Furthermore, effects on non-cognitive outcomes (e.g., neuropsychiatric symptoms, quality of life) are largely unclear as they were often not considered in randomized controlled trials (RCTs) so far. Also, rare information is available for the specific group of PD patients with (yet) no cognitive impairment or PD patients with mild cognitive impairment (PD-MCI) diagnosed (or excluded) according to established criteria. And even less is known regarding cognitive interventions in PDD patients $[11,12]$. Up to now, there are no systematic reviews and meta-analyses examining the specific benefits of other cognitive approaches apart from cognitive training and cognitive rehabilitation (e.g., cognitive stimulation, reminiscence approaches). Hence, to achieve the long-term goal that effective cognitive interventions can be integrated into clinical routine, a lot of work has to be done in the next decades (Table 1).
Within the next 20 years...

1. Knowledge about and awareness of cognitive impairment in PD: The knowledge about cognitive impairment in PD and its management has substantially improved. Clinicians are aware of the fact that cognitive impairment is a frequent and disabling symptom of PD. Cognitive change in medical history and screening for cognitive impairment is routinely conducted in all newly diagnosed PD patients and during the course of the disease.

2. Evidence-based cognitive interventions in clinical routine: Evidence on the short- and long-term efficacy of standardized cognitive interventions in PD patients has been gathered with large multicenter RCTs, so that recommendations for clinical decision-making exist, and corresponding treatments with standardized manuals are available. Cost-efficacy studies, which are lacking so far, have been conducted. Cognitive interventions are implemented in clinical practice as an integral part of the multidisciplinary therapy regime. They are provided by qualified staff both in ambulant as well as long-term care settings. Staff trainings are widely available. The questions who

Table 1

Key ideas for the to do's with regard to cognitive interventions in Parkinson's disease for the next 20 years

\section{Development of interventions}

$\checkmark$ Standardized cognitive intervention manuals have to be developed for different approaches (e.g., cognitive training, cognitive rehabilitation, and cognitive stimulation) for patients with different cognitive stages (without cognitive impairment, PD-MCI, PDD).

$\checkmark$ Further interventions targeting cognitive functions as one aspect (e.g., combined motor-cognitive trainings, mindfulness training) and including digital techniques (e.g., serious games, virtual reality) and further approaches supported by artificial intelligence have to be developed.

$\checkmark$ Home-based variants of these interventions have to be developed.

\section{Studies}

$\checkmark$ Large multicenter RCTs which examine the efficacy and the best program characteristics (e.g., intensity and frequency of intervention, group versus individual training) of these different cognitive approaches have to be conducted

- in PD patients with different cognitive stages (prodromal PD, PD, PD-SCI, PD-MCI, PDD),

- in PD patients with different clinical profiles (e.g., regarding motor subtypes, neuropsychiatric symptoms),

- in different settings (community-dwelling versus institutionalized),

- considering more sensitive cognitive and non-cognitive outcomes including patient-centered outcomes and biomarkers,

- including methods to analyze the underlying mechanisms of cognitive and neural plasticity induced by these interventions.

$\checkmark$ Studies which examine the efficacy of multidomain lifestyle interventions in individuals with prodromal PD have to be conducted.

$\checkmark$ Analysis of the cost-efficacy of these interventions in these groups has to be performed.

\section{Clinical practice}

$\checkmark$ Cognitive intervention manuals that are effective have to be made available for clinical practice.

$\checkmark$ Effective cognitive interventions have to be integrated into clinical routine.

\section{Broader concepts}

$\checkmark$ The society - and especially individuals at risk for neurodegenerative disease - has to be educated with regard to the concept of cognitive reserve in order to promote a brain protecting lifestyle.

Abbreviations: PD, Parkinson's disease; PDD, Parkinson's disease dementia; PD-MCI, Parkinson's disease with mild cognitive impairment; PD-SCI, Parkinson's disease with subjective cognitive impairment; RCT, randomized controlled trial. 
will conduct the interventions (neuropsychologists, other?), and how patients get access have been clarified.

3. Consideration of heterogeneous patient groups and settings: Clear evidence exists for the efficacy of cognitive interventions in PD patients in different cognitive stages including PD-MCI and PDD (mild, moderate, severe) diagnosed according to established criteria (cf. [13, 14]), both for community-dwelling individuals and institutionalized patients (e.g., hospitals, nursing homes), and with different potentially modifying neuropsychiatric symptom profiles (e.g., depression, apathy). Evidence has also been gathered for PD patients without objective cognitive impairment, but with a high risk to develop cognitive decline. These include patients with subjective cognitive impairment (SCI) (in analogy to SCI in pre-Alzheimer stages [15]), but also PD patients without SCI who can be identified as having a high risk for cognitive decline by risk algorithms which have been further developed (based on current approaches, e.g., [16, 17]). Accordingly, specific recommendations and therapies for these groups of individuals and patients exist (Fig. 1).

4. Dementia prevention starting in prodromal PD: It is possible to identify prodromal PD more reliably [18]. Cognitive changes in this disease stage, for which data are inconclusive yet [19], have been investigated thoroughly in longitudinal studies, and trajectories to cognitive dysfunction are clear. Following large multicenter trials for prevention of dementia with individuals in prodromal stages of Alzheimer's disease examining the effect of multidomain lifestyle intervention including cognitive interventions and exercise (e.g., [20]) but also management of cardio-vascular disease and other disease factors [21] have also been conducted in patients with prodromal PD. Data exist regarding their efficacy to delay symptom onset with regard to motor and cognitive symptoms. Notably, today's view is that many reasons exist to be ambitious about prevention of dementia, and that cognitive interventions may play an important role [21, 22].

5. Relevant outcome measures: Cognitive outcome measures (partly digital, more economic) that are much more sensitive to detect cognitive dysfunction and change of function and show few learning effects in PD have been developed and are used in studies [23]. These may include, e.g., wearable devices or passive sensors that collect continuous, objective data during activities of daily living which may be more sensitive

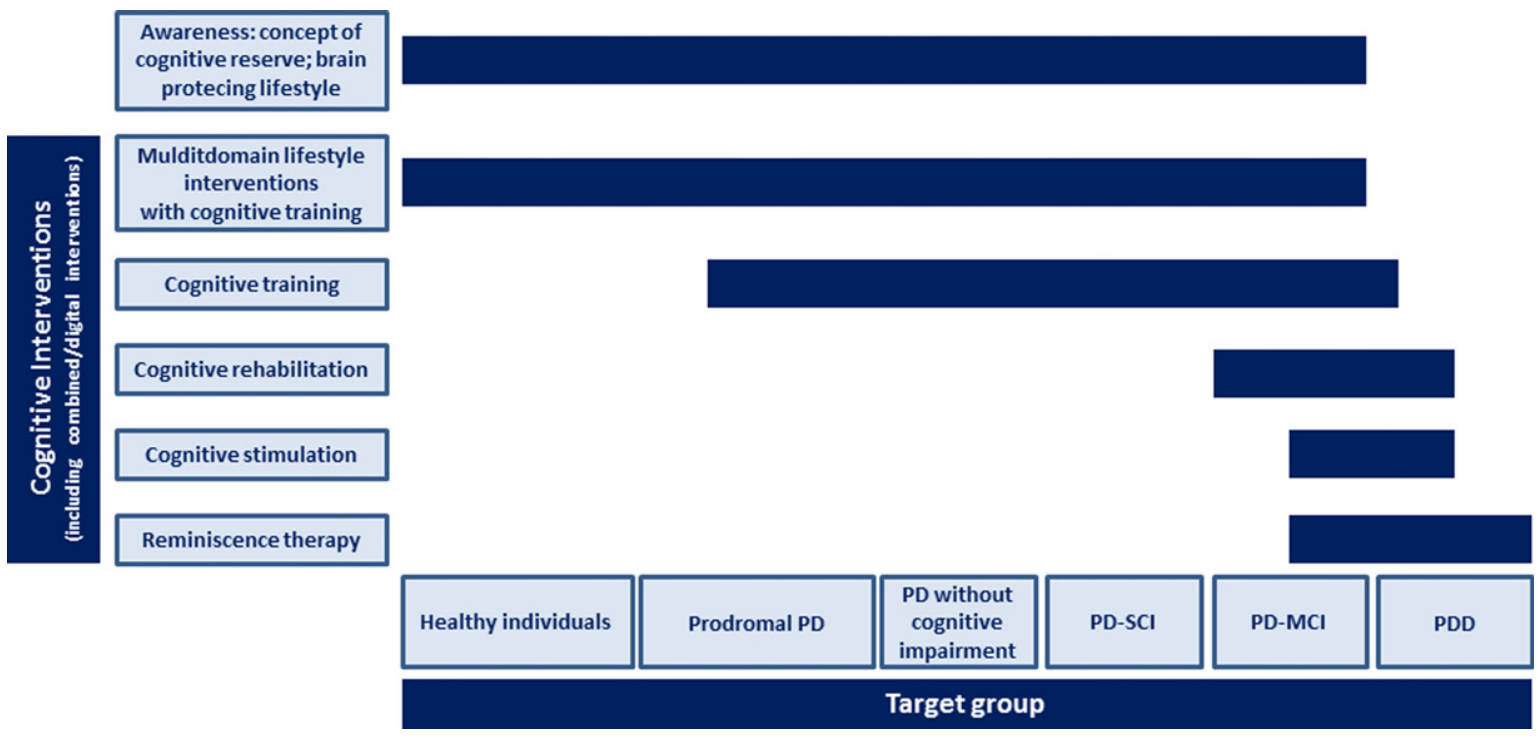

Fig. 1. Possible scheme for cognitive approaches in Parkinson's disease in 20 years. Abbreviations: PD, Parkinson's disease; PDD, Parkinson's disease dementia; PD-MCI, Parkinson's disease with mild cognitive impairment; PD-SCI, Parkinson's disease with subjective cognitive impairment. 
to subtle changes of function and are more realistic indicators of cognitive function than lab-based tests [24]. Biomarkers for cognitive training effects have also been defined (e.g., parameters of structural and functional brain imaging [25], EEG [26], brain-derived neurotrophic factor (BDNF; [27]) and other neurotrophic factors). Furthermore, studies have considered not only established cognitive or non-cognitive outcomes (such as neuropsychiatric symptoms like depression and apathy, activities of daily living, or quality of life), but also patientcentered outcomes (Patient Reported Outcome Measures (PROMs), Patient Reported Experience Measures (PREMS)) to assess those aspects that are most important for the individuals as well as subjective evaluation of intervention success (e.g., using training diaries to measure training motivation and to evaluate each session). Today, studies are just about to begin to include these important variables (e.g., a study conducting goal-oriented cognitive rehabilitation in PDD patients [28]; recommendations for core outcome measures for dementia interventions partly based on patient involvement [29]). Furthermore, in 2038 studies have provided information on which outcomes are decisive for patients in different cognitive stages and with different clinical (and maybe sociodemographic, genetic etc.) profiles.

6. Different approaches of cognitive interventions: The spectrum of cognitive interventions that has been developed and evaluated for PD patients in different cognitive stages has broadened substantially (Fig. 1). A clear-cut nomenclature for these interventions, elaborated by the international expert community, exists and is commonly used by scientists and clinicians. Interventions include cognitive training (i.e., standardized paper-and-pencil or computerized tasks provided in individual or group sessions targeting particular cognitive functions to improve or maintain these isolated functions [30, 31]; strategy training; often in combination with psychoeducation), cognitive rehabilitation (i.e., individualized approach targeting the patient's everyday context and developing strategies for improving or maintaining performance in activities of daily living [30, 31]), and cognitive stimulation (i.e., cognitively stimulating activities in small groups targeting the stabilization or improvement of global cognitive and social functioning primarily in patients with dementia [30, 32]; often in combination with reminiscence) and maybe further approaches. Those elements of these interventions that are most effective in enhancing cognition with transfer effects on everyday life and other relevant outcomes have been identified. Digital techniques including serious games (e.g., [33]), virtual reality training [34] and further to be defined interventions (e.g., neurofeedback training and brain-computer interface training) play an important role. Cognitive aspects and underlying neural mechanisms of mindfulness-based interventions, both aspects of which have only rarely been studied, but with promising results in, e.g., healthy elderly $[35,36]$ and, e.g., patients with non-PD dementia [37], have been clarified, and their possible role as a cognitive intervention in $\mathrm{PD}$ is evident.

7. Motivating interventions: Cognitive interventions exist that make fun and are motivating so that patients show high compliance in the long-term. This important goal has been achieved by involving patients in the development of cognitive interventions. More precisely, qualitative research (e.g., in form of focus groups), feasibility evaluations, and principles of user-centered design and content have consequently been integrated into the development process.

8. Home-based approaches: Evaluated homebased interventions are common for those who like to do training at home, and especially for those in rural areas with limited access to ambulant therapies. By telemedicine techniques, training can easily be supervised and adapted to the individual cognitive level and training progress by experts. As valid and reliable digital cognitive tests are available, training progress can be monitored on a regular basis.

9. Clear therapy recommendations: Data exist which inform clinicians about the best frequency and intensity for different forms of cognitive interventions in PD patients in different cognitive stages. The question how often (once, once a year, more frequently - or continuously?) training programs have to be 
conducted and what booster training adds to benefits [38] can be answered. Regarding longterm effects, the question whether cognitive interventions (or which intervention type in which PD patients) only attenuate or rather delay the trajectory to cognitive decline has been answered [38].

10. Cognitive-motor-interplay: The interplay between cognitive and motor functions as well as specific symptoms such as freezing [39] in PD has been defined concisely [40]. Effects of cognitive training on these outcomes, which are currently under discussion [41, 42], are clear.

11. Combined approaches: Different forms of combined motor-cognitive trainings have been thoroughly studied and are available as standard interventions. Data on the efficacy of further combined interventions are also available and have been transferred into clinical practice accordingly. They may include cognitive interventions with other therapies with the potential to enhance cognition (e.g., playing an instrument [43], other creative therapies), but also cognitive training or brain interface trainings in combination with brain stimulation techniques (tDCS and TMS) [6] or set-ups of deep brain stimulation targeting cognitive functions according to neurofeedback. Furthermore, the additional benefit of combining cognitive interventions with antidementia drugs is clear (which has exclusively been shown in non-PD patients with dementia so far, e.g., [44]), and has led to adapted therapy regimes. Assumed that disease-modifying drugs are available, data has also been gathered with regard to combining these with nonpharmacological interventions (among them cognitive approaches) in patients in early phases of the disease. The role of potential pharmacological cognitive enhancers in the prevention and therapy of cognitive dysfunction in PD has been investigated [45].

12. Mechanism and prediction models: Underlying mechanisms of neural and cognitive plasticity induced by cognitive and combined interventions in PD patients have been investigated multimethodically including, e.g., functional and structural brain imaging techniques, electrophysiological methods, and blood analysis. Furthermore, prediction analyses have identified factors that influence the intervention benefit. These may include sociodemographic variables (e.g., age, education, gender), clinical parameters (e.g., disease duration and severity, motor subtype, medication, comorbidities), severity of cognitive dysfunction and cognitive profile (e.g., amnestic versus non-amnestic single versus multiple domain PD-MCI), and genetics (e.g., carriers versus non-carriers of ApoE, GBA, MAPT). This knowledge has led to more targeted and efficient interventions.

13. Personalized interventions: Cognitive (and combined) interventions have entered the era of personalized medicine. This means that interventions are tailored to the individual (cognitive/motor/genetic etc.) profile and preferences (e.g., group versus individual training, digital versus paper and pencil training, gaming versus classical training), probably supported by machine learning techniques. Compiling an individual training plan including cognitive or combined intervention is easy as it follows an evidence-based algorithm. Digital tools are available for the clinician in which local facilitators of these interventions are listed and can directly be contacted.

More generally, the awareness of the concept of cognitive reserve for PD patients [46] has increased substantially, and the broader concept of cognitive reserve and possibilities for the prevention of age-related cognitive decline and dementia is acknowledged in the population, promoted by research driven society based campaigns (e.g., https://www.wezijnzelfhetmedicijn.nl/in the Netherlands), so that more people wittingly follow a healthy and brain protecting lifestyle including more mental, physical and social activities and a healthy diet.

\section{ACKNOWLEDGMENTS}

This paper represents independent research [part] funded by the National Institute for Health Research (NIHR) Biomedical Research Centre at South London and Maudsley NHS Foundation Trust and King's College London. The views expressed are those of the author(s) and not necessarily those of the NHS, the NIHR or the Department of Health. DA is a Royal Society Wolfson Research Merit Award Holder and would like to thank the Wolfson Foundation and the Royal Society for their support. 


\section{CONFLICT OF INTEREST}

EK has received grants from the German Ministry of Education and Research, the GermanParkinsonFonds, the German Parkinson Society; honoraria from: Oticon GmbH, Hamburg, Germany; Lilly Pharma GmbH, Bad Homburg, Germany; Bernafon AG, Bern, Switzerland; Desitin GmbH, Hamburg, Germany. DA has received research support and/or honoraria from Astra-Zeneca, H. Lundbeck, Novartis Pharmaceuticals and GE Health, and serves as paid consultant for $\mathrm{H}$. Lundbeck, Eisai, and Axovant. AKF has received a grant from the German Parkinson Society, and honoraria from ProLog Wissen GmbH, Cologne, Germany.

\section{REFERENCES}

[1] Kowal SL, Dall TM, Chakrabarti R, Storm MV, Jain A (2013) The current and projected economic burden of Parkinson's disease in the United States. Mov Disord 28, 311-318.

[2] Hely MA, Reid WG, Adena MA, Halliday GM, Morris JG (2008) The Sydney multicenter study of Parkinson's disease: The inevitability of dementia at 20 years. Mov Disord 23, 837-844.

[3] Aarsland D, Kurz MW (2010) The epidemiology of dementia associated with Parkinson's disease. Brain Pathol 20, 633-639.

[4] Hindle JV, Petrelli A, Clare L, Kalbe E (2013) Nonpharmacological enhancement of cognitive function in Parkinson's disease: A systematic review. Mov Disord 28, 1034-1049.

[5] Leung IH, Walton CC, Hallock H, Lewis SJ, Valenzuela M, Lampit A (2015) Cognitive training in Parkinson disease: A systematic review and meta-analysis. Neurology 85, 18431851.

[6] Lawrence BJ, Gasson N, Bucks RS, Troeung L, Loftus AM (2017) Cognitive training and noninvasive brain stimulation for cognition in Parkinson's disease: A meta-analysis. Neurorehabil Neural Repair 31, 597-608.

[7] Alzahrani H, Venneri A (2018) Cognitive rehabilitation in Parkinson's disease: A systematic review. J Parkinsons Dis 8, 233-245.

[8] Díez-Cirarda M, Ojeda N, Peña J, Cabrera-Zubizarreta A, Lucas-Jiménez O, Gómez-Esteban JC, Gómez-Beldarrain MÁ, Ibarretxe-Bilbao N (2017) Long-term effects of cognitive rehabilitation on brain, functional outcome and cognition in Parkinson's disease. Eur J Neurol 25, 5-12.

[9] Díez-Cirarda M, Ojeda N, Peña J, Cabrera-Zubizarreta A, Lucas-Jiménez O, Gómez-Esteban JC, Gómez-Beldarrain MÁ, Ibarretxe-Bilbao N (2018) Increased brain connectivity and activation after cognitive rehabilitation in Parkinson's disease: A randomized controlled trial. Brain Imaging Behav 11, 1640-1651.

[10] Cerasa A, Gioia MC, Salsone M, Donzuso G, Chiriaco C, Realmuto S, Nicoletti A, Bellavia G, Banco A, D'amelio M, Zappia M, Quattrone A (2014) Neurofunctional correlates of attention rehabilitation in Parkinson's disease: An explorative study. Neurol Sci 35, 1173-1180.
[11] Kalbe E, Folkerts AK (2016) Cognitive training in Parkinson's disease - a new therapy option? Fortschr Neurol Psychiatr 84(Suppl 1), S24-S35.

[12] McCormick SA, McDonald KR, Vatter S, Orgeta V, Poliakoff E, Smith S, Silverdale MA, Fu B, Leroi I (2017) Psychosocial therapy for Parkinson's-related dementia: Study protocol for the INVEST randomised controlled trial. BMJ Open 7, e016801.

[13] Litvan I, Goldman JG, Tröster AI, Schmand BA, Weintraub D, Petersen RC, Mollenhauer B, Adler CH, Marder K, Williams-Gray CH, Aarsland D, Kulisevsky J, RodriguezOroz MC, Burn DJ, Barker RA, Emre M (2012) Diagnostic criteria for mild cognitive impairment in Parkinson's disease: Movement Disorder Society Task Force guidelines. Mov Disord 27, 349-356.

[14] Emre M, Aarsland D, Brown R, Burn DJ, Duyckaerts C, Mizuno Y, Broe GA, Cummings J, Dickson DW, Gauthier S, Goldman J, Goetz C, Korczyn A, Lees A, Levy R, Litvan I, McKeith I, Olanow W, Poewe W, Quinn N, Sampaio C, Tolosa E, Dubois B (2007) Clinical diagnostic criteria for dementia associated with Parkinson's disease. Mov Disord 22, 1689-1707.

[15] Mendonça MD, Alves L, Bugalho P (2016) From subjective cognitive complaints to dementia: Who is at risk? A systematic review. Am J Alzheimers Dis Other Demen 31, 105-114.

[16] Caspell-Garcia C, Simuni T, Tosun-Turgut D, Wu IW, Zhang Y, Nalls M, Singleton A, Shaw LA, Kang JH, Trojanowski JQ, Siderowf A, Coffey C, Lasch S, Aarsland D, Burn D, Chahine LM, Espay AJ, Foster ED, Hawkins KA, Litvan I, Richard I, Weintraub D, Parkinson's Progression Markers Initiative (PPMI) (2017) Multiple modality biomarker prediction of cognitive impairment in prospectively followed de novo Parkinson disease. PLoS One 12, e0175674.

[17] Liu G, Locascio JJ, Corvol JC, Boot B, Liao Z, Page K, Franco D, Burke K, Jansen IE, Trisini-Lipsanopoulos A, Winder-Rhodes S, Tanner CM, Lang AE, Eberly S, Elbaz A, Brice A, Mangone G, Ravina B, Shoulson I, Cormier-Dequaire F, Heutink $\mathrm{P}$, van Hilten JJ, Barker RA, Williams-Gray CH, Marinus J, Scherzer CR, HBS, CamPaIGN, PICNICS, PROPARK, PSG, DIGPD, PDBP (2017) Prediction of cognition in Parkinson's disease with a clinical-genetic score: A longitudinal analysis of nine cohorts. Lancet Neurol 16, 620-629.

[18] Berg D, Postuma RB, Adler CH, Bloem BR, Chan P, Dubois B, Gasser T, Goetz CG, Halliday G, Joseph L, Lang AE, Liepelt-Scarfone I, Litvan I, Marek K, Obeso J, Oertel W, Olanow CW, Poewe W, Stern M, Deuschl G (2015) MDS research criteria for prodromal Parkinson's disease. Mov Disord 30, 1600-1611.

[19] Fengler S, Liepelt-Scarfone I, Brockmann K, Schäffer E, Berg D, Kalbe E (2017) Cognitive changes in prodromal Parkinson's disease: A review. Mov Disord 32, 1655-1666.

[20] Rosenberg A, Ngandu T, Rusanen M, Antikainen R, Bäckman L, Havulinna S, Hänninen T, Laatikainen T, Lehtisalo J, Levälahti E, Lindström J, Paajanen T, Peltonen M, Soininen H, Stigsdotter-Neely A, Strandberg T, Tuomilehto J, Solomon A, Kivipelto M (2018) Multidomain lifestyle intervention benefits a large elderly population at risk for cognitive decline and dementia regardless of baseline characteristics: The FINGER trial. Alzheimers Dement 14, 263-270.

[21] Livingston G, Sommerlad A, Orgeta V, Costafreda SG, Huntley J, Ames D, Ballard C, Banerjee S, Burns A, 
Cohen-Mansfield J, Cooper C, Fox N, Gitlin LN, Howard R, Kales HC, Larson EB, Ritchie K, Rockwood K, Sampson EL, Samus Q, Schneider LS, Selbæk G, Teri L, Mukadam N (2018) Dementia prevention, intervention, and care. Lancet 390, 2673-2734.

[22] Goldman JG, Vernaleo BA, Camicioli R, Dahodwala N, Dobkin RD, Ellis T, Galvin JE, Marras C, Edwards J, Fields J, Golden R, Karlawish J, Levin B, Shulman L, Smith G, Tangney C, Thomas CA, Tröster AI, Uc EY, Coyan N, Ellman C, Ellman M, Hoffman C, Hoffman S, Simmonds D (2018) Cognitive impairment in Parkinson's disease: A report from a multidisciplinary symposium on unmet needs and future directions to maintain cognitive health. NPJ Parkinsons Dis 4, 19.

[23] McCaffrey P, Strobel G (2018) Cognitive testing is getting faster and better. Alzforum. https://www.alzforum.org/news/ conference-coverage/cognitive-testing-getting-faster-andbetter, Posted on 09 December 2017, Accessed September 19, 2018.

[24] Gold M, Amatniek J, Carrillo MC, Cedarbaum JM, Hendrix JA, Miller BB, Robillard JM, Rice JJ, Soares H, Tome MB, Tarnanas I, Vargas G, Bain LJ, Czaja SJ (2018) Digital technologies as biomarkers, clinical outcomes assessment, and recruitment tools in Alzheimer's disease clinical trials. Alzheimers Dement (NY) 4, 234-242.

[25] Belleville S, Bherer L (2012) Biomarkers of cognitive training effects in aging. Curr Transl Geriatr Exp Gerontol Rep 1, 104-110.

[26] Santarnecchi E, Khanna AR, Musaeus CS, Benwell CSY, Davila P, Farzan F, Matham S, Pascual-Leone A, Shafi MM, Honeywell SHARP Team authors (2017) EEG microstate correlates of fluid intelligence and response to cognitive training. Brain Topogr 30, 502-520.

[27] Rahe J, Becker J, Fink GR, Kessler J, Kukolja J, Rahn A, Rosen JB, Szabados F, Wirth B, Kalbe E (2015) Cognitive training with and without additional physical activity in healthy older adults: Cognitive effects, neurobiological mechanisms, and prediction of training success. Front Aging Neurosci 7, 187.

[28] Hindle JV, Watermeyer TJ, Roberts J, Brand A, Hoare Z, Martyr A, Clare L (2018) Goal-orientated cognitive rehabilitation for dementias associated with Parkinson's disease-A pilot randomised controlled trial. Int J Geriatr Psychiatry 33, 718-728.

[29] Webster L, Groskreutz D, Grinbergs-Saull A, Howard R, O'Brien JT, Mountain G, Banerjee S, Woods B, Perneczky R, Lafortune L, Roberts C, McCleery J, Pickett J, Bunn F, Challis D, Charlesworth G, Featherstone K, Fox C, Goodman C, Jones R, Lamb S, Moniz-Cook E, Schneider J, Shepperd S, Surr C, Thompson-Coon J, Ballard C, Brayne C, Burke O, Burns A, Clare L, Garrard P, Kehoe P, Passmore P, Holmes C, Maidment I, Murtagh F, Robinson L, Livingston G (2017) Development of a core outcome set for disease modification trials in mild to moderate dementia: A systematic review, patient and public consultation and consensus recommendations. Health Technol Assess $\mathbf{2 1}$, 1-192.

[30] Clare L, Woods RT (2004) Cognitive training and cognitive rehabilitation for people with early-stage Alzheimer's disease: A review. Neuropsychol Rehabil 14, 385-401.

[31] Bahar-Fuchs A, Clare L, Woods B (2013) Cognitive training and cognitive rehabilitation for mild to moderate
Alzheimer's disease and vascular dementia. Cochrane Database Syst Rev 6, CD003260.

[32] Woods B, Aguirre E, Spector AE, Orrell M (2012) Cognitive stimulation to improve cognitive functioning in people with dementia. Cochrane Database Syst Rev 2, CD005562.

[33] van de Weijer SC, Duits AA, Bloem BR, Kessels RP, Jansen JF, Köhler S, Tissingh G, Kuijf ML (2016) The Parkin'Play study: Protocol of a phase II randomized controlled trial to assess the effects of a health game on cognition in Parkinson's disease. BMC Neurol 16, 209.

[34] Dockx K, Bekkers EM, Van den Bergh V, Ginis P, Rochester L, Hausdorff JM, Mirelman A, Nieuwboer A (2016) Virtual reality for rehabilitation in Parkinson's disease. Cochrane Database Syst Rev 12, CD010760.

[35] Berk L, van Boxtel M, van Os J (2017) Can mindfulnessbased interventions influence cognitive functioning in older adults? A review and considerations for future research. Aging Ment Health 21, 1113-1120.

[36] Young KS, van der Velden AM, Craske MG, Pallesen KJ, Fjorback L, Roepstorff A, Parsons CE (2018) The impact of mindfulness-based interventions on brain activity: A systematic review of functional magnetic resonance imaging studies. Neurosci Biobehav Rev 84, 424-433.

[37] Russell-Williams J, Jaroudi W, Perich T, Hoscheidt S, El Haj M, Moustafa AA (2018) Mindfulness and meditation: Treating cognitive impairment and reducing stress in dementia. Rev Neurosci 29, 791-804.

[38] Walton CC, Naismith SL, Lampit A, Mowszowski L, Lewis SJ (2017) Cognitive Training in Parkinson's Disease. Neurorehabil Neural Repair 31, 207-216.

[39] Ricciardi L, Bloem BR, Snijders AH, Daniele A, Quaranta D, Bentivoglio AR, Fasano A (2014) Freezing of gait in Parkinson's disease: The paradoxical interplay between gait and cognition. Parkinsonism Relat Disord 20, 824-829.

[40] Middleton FA, Strick PL (2000) Basal ganglia and cerebellar loops: Motor and cognitive circuits. Brain Res Brain Res Rev 31, 236-250.

[41] Walton CC, Shine JM, Mowszowski L, Naismith SL, Lewis SJ (2014) Freezing of gait in Parkinson's disease: Current treatments and the potential role for cognitive training. Restor Neurol Neurosci 32, 411-422.

[42] Dibilio V, Nicoletti A, Mostile G, Portaro G, Luca A, Patti F, Zappia M(2017) Computer-assisted cognitive rehabilitation on freezing of gait in Parkinson's disease: A pilot study. Neurosci Lett 654, 38-41.

[43] Bugos J (2018) Protocol for a randomized controlled trial of piano training on cognitive and psychosocial outcomes. Ann N Y Acad Sci. doi: 10.1111/nyas. 13663

[44] Requena C, López Ibor MI, Maestú F, Campo P, López Ibor JJ, Ortiz T (2004) Effects of cholinergic drugs and cognitive training on dementia. Dement Geriatr Cogn Disord 18, 50-54.

[45] Choi SH, Bylykbashi E, Chatila ZK, Lee SW, Pulli B, Clemenson GD, Kim E, Rompala A, Oram MK, Asselin C, Aronson J, Zhang C, Miller SJ, Lesinski A, Chen JW, Kim DY, van Praag H, Spiegelman BM, Gage FH, Tanzi RE (2018) Combined adult neurogenesis and BDNF mimic exercise effects on cognition in an Alzheimer's mouse model. Science 361, eaan8821.

[46] Bohnen JLB, Müller MLTM, Haugen J, Bohnen NI (2017) Mentally stimulating activities associate with better cognitive performance in Parkinson disease. J Neural Transm (Vienna) 124, 1205-1212. 